\title{
The life and works of Dr Brian Bernard Newbould (28nd Jan 1934-25th Nov, 2016) B. Pharm, FR PharmS, PhD
}

\author{
K. D. Rainsford ${ }^{1}$
}

Received: 10 November 2020 / Accepted: 11 November 2020 / Published online: 27 January 2021

(c) Springer Nature Switzerland AG 2021

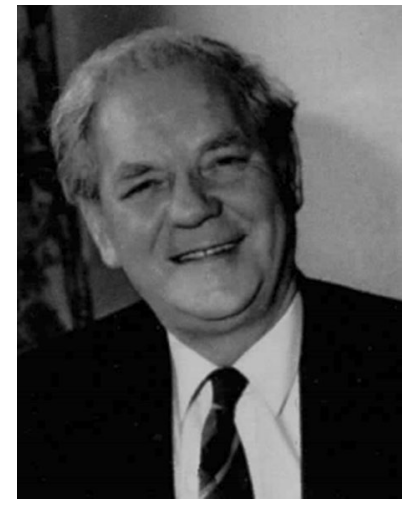

Brian Newbould was a unique research scientist of high standing and a scientific administrator who spent most of his working life in the pharmaceutical industry (ICI Pharmaceuticals Division (ICI plc) Macclesfield, UK, which in 1990 became Zeneca Ltd). Most of his research and direction was devoted to the development of anti-arthritic agents and drugs affecting the endocrine and immune systems. These contributions are celebrated here along with the extensive support he gave to research organizations and individuals as well as in academic leadership and in promotion of high standards in academe and industry. Brian was especially generous in giving clear and invaluable advice to colleagues and showed inspired thinking and direction of research in his field.

Britain has been especially fortunate to have had outstanding industry-based scientists like Brian who made major contributions to the discovery and therapeutic application in the treatment of pain and arthritic conditions in the post- World War II period. Among these outstanding

K. D. Rainsford

editor@inflammopharmacology.com

1 Emeritus Professor of Biomedical Sciences, Biomedical Research Centre, Sheffield Hallam University, Howard Street, Sheffield, England S1 1WB, UK scientists in this field are Drs (now Professors) Stewart Adams (Boots), Ian Hunneyball (Boots, BASF, then Evotec), Bill Dawson (Ely Lilly), to name a few. Like Brian, Stewart Adams and Bill Dawson were pharmacists by training. This background would have given them a thorough basis to drug discovery and development.

Brian appears to have started life in Sheffield having passed the II-plus examination at Abbey Lane Primary School (1939-45) in Sheffield. He passed eight subjects for school certificate General Certificate of Education (GCE) and Physics, Chemistry followed by Biology at Advanced Level at Nether Edge Grammar School (1945-1952). It is worth noting that he must have experienced the impact of bombing and destruction of Sheffield during WW2 and the post-recovery. In 1952-54 he was apprenticed in Pharmacy to Boots the Chemists Ltd, Sheffield. In 1954-57 he studied pharmacy at the School of Pharmacy, Leicester College of Technology where he graduated B Pharm (Honours) as an External Student at the University of London and was awarded 5 certificates of honour and 5 prizes. He was also showing signs of the ability to organize people having been elected Chairman of the Pharmacy Students Association and other committees. He passed the qualifying examination for a membership of the Pharmaceutical Society of Great Britain in 1957 and in 1978 was elected fellow of that society. In 1957-59 he was awarded the Ciba Research Scholarship in Pharmacology at Sheffield University where he conducted research in the Department of Pharmacology and Therapeutics under the supervision of the late GM Wilson and Dr R Kilpatrick and was awarded a PhD for a thesis entitled "The Pharmacology of some new Sulphonamides".

In 1959, Brian was appointed Research Technical Officer at ICI Pharmaceuticals, Alderley Park, Macclesfield, Cheshire, UK, where he formed a unit which was aimed at detecting and evaluating new compounds for the treatment of rheumatoid arthritis. This disease was then considered a major medical problem which presented formidable therapeutic challenges in that period. Brian and his team developed 
and refined the mycobacterial adjuvant-induced arthritis in rats, which was considered a model for rheumatoid arthritis. This work was based on a description by Stoerck, Bielinski and Budzilovich (1954) and further developed by Dr Carl Pearson of the School of Medicine, University of California in Los Angeles (UCLA) (Pearson 1956, 1959; Pearson and Wood 1959, 1963) who is considered to have been a major pioneer in the development of this animal model (Whitehouse 2007). Around the time of Carl Pearson's papers, Brian had established this model and later published several important papers on adjuvant-induced polyarthritis (AA) (Newbould 1963a, 1963b, 1964a, 1964b, 1964c, 1964d) his focus in these studies was on (a) the role of lymph nodes and lymphocytes in the development of polyarthritis, (b) the use of the AA model for the discovery of drugs that affect the disease process in RA (Newbould 1964a, 1964b, 1964c, 1964d, 1965a, 1965b,1965c; 1967, 1968, 1969; Franklin et al. 1966; Hepworth et al. 1968a, 1969b). The studies on the role of lymphocytes and effects of lymphatic drainage on the expression of the disease were fundamental to understanding of the immuno-pathogenesis of the disease. Further refinement of the lymphocyte-depletion studies in AA (Whitehouse et al. 1969; Koga et al. 1976) served as a basis for highly significant investigations by Carl Pearson in which he and colleagues showed that depletion of lymphocytes in patients with rheumatoid arthritis led to amelioration of the disease (Pearson 1976).

A very important development in Brian's career as well as his being significant for scientific investigations of AA and other auto-immune conditions, experimental allergic encephalomyelitis (Newbould 1966b; Newbould et al. 2019) and experimental allergic myositis (Morgan et al. 1971) both in rats which led Brian to take leave of absence in 1968-1969 to work with Carl Pearson at UCLA. This work involved the production and passive transfer of various immunologic diseases in laboratory animals. Upon his return to ICI Pharmaceutics Division in 1969 he became Manager of the Biology Research Department where he managed 200 scientists involved in biological and pharmacological research and, after 1973, this included 120 researchers involved in biochemical research. He was then seconded to the Senior Management team involved in the Central Laboratory comprising 300 leading scientists who were involved in exploring frontiers of research in chemistry, polymer science, biotechnology, process technology and materials science. He worked under Dr (later Sir) Tom McKillop, who subsequently became CEO of Zeneca, and later of Astra-Zeneca (1999-2006). Sir Tom gave a brilliant eulogy, "Tribute from Colleagues" at the Service of Celebration and Thanksgiving at St. Oswald's Parish Church, Bollington on 14th December 2016, following Brian's death on 25th November 2016. Sir Tom talked of Brian's achievements in using the adjuvant arthritis model for the discovery of ICI 54.450, or fenclozic acid (Myalex) (Newbould 1969a, b), but which was later withdrawn from patients with RA because of hepatotoxicity (Chalmers et al. 1969; Dudley Hart et al. 1970). Later studies using ${ }^{14} \mathrm{C}$-radiolabelled fenclozic showed that this was due to covalent binding of reactive metabolites (Rodrigues et al. 2013). Many studies with NSAIDs and other drugs that have been found to be hepatotoxic, have shown that liver and skin toxicity is related to drug activation by liver cytochromes $\mathrm{P} 450$ to form reactive metabolites. The early work with fenclozic proved to be the basis for case histories in the hepatic adverse reaction of many drugs metabolized via the liver.

Brian also oversaw work by the late Dr Mike Billingham in which the AA model was used to discover another remarkable NSAID, clobuzarit $\left(\mathrm{Clozic}^{\circledR}\right)$ (Billingham and Rushden 1985). Very sadly, this drug was also withdrawn because of what is to be believed to have been reactive molecules during manufacturing processes. As said by Sir Tom McKillop, "despite these disappointments, Brian was always upbeat, always positive, a steadying influence and inspiration to all his colleagues". Was this a result of post-war influences in which he learned so much from the "School of Hard Knocks", then an ever-pervasive influence especially in Yorkshire and other areas of the industrial heartland of Britain? Perhaps it was from his great energy and abilities as an outstanding golfer. Brian also had outstanding and impressive managerial skills as witnessed by his skills as a senior Director and Scientific Advisory Board member of ICI Pharmaceutics (1975-1990) and Director of International Research Affairs of Zeneca Ltd (1990-1993), Director Roslin Institute (Edinburgh) and chair of Finance Committee (1995-2000), Governor and Vice Chairman Stockport College, Chair of Audit Committee (1993-2003), Member of an European Community Research Assessment Panel (1995-2000), Member of the Nuffield Council on Bioethics (1991-1999), Member of Council Foundation for Science and Technology, Member of the Scientific Committee of the Royal Pharmaceutical Society (1993-1998), Chairman of the Science Advisory Board, Centre for Genome Research (1993-1997), Member of the OST Advisory Committee, Asia and Pacific, Chairman of the Pharmacy Panel, Research Assessment Exercise UK, Higher Education Founding Council (1995-1997), Member Advisory Committee Japan Centre, University of Essex, President Research and Development Society (1996), Member of the Biological Science Committee (1984-1986) and Member of the Bioscience Education and Training Panel UK Govt., Science and Engineering Research Council (1988-1993), Member of the Animal Procedures Committee, UK Govt. Home Office (1983-1984), Chairman of the Scientific Committee of the Association of the British Pharmaceutical Industry (ABPI) (1980-1987) and Chairman of Japan Coordinating Committee of the ABPI (1985-1990). His wide-ranging 
international and national activities and frequent invitations to scientific conferences and board memberships attest to his immense breadth of knowledge, skills and directing and managing diverse groups and special people skills of which he was renowned.

For his outstanding contributions to research and professional activities, Brian received many awards, among then Fellow of the Royal Pharmaceutical Society (1978), Honorary Member of the British Pharmacological Society (1996), and the Duncan Davies Memorial Medal from the Research and Development Society (1992).

I had known of Brian's work from the 1970s both from the early days working on animal models of arthritic and inflammatory diseases and my own experiences working on the actions and mechanisms of anti-inflammatory, immunoregulatory and other drugs. When I took up appointment as Professor and Head of the Division of Biomedical Sciences (1991) and later (1996) Director of the Biomedical Research Centre, I arranged for the appointment (1994) of Brian as a Visiting Fellow and advisor to our research group. What a blessing this was for he was a fountain of knowledge and wisdom to whom I often turned for help and advice. Not only was he incisive, but a warm and inviting personality. I learnt much from Brian. His death at the young age of $82 \mathrm{yrs}$ was a shock to many but proves the adage "only the good die young" R.I.P.

Acknowledgements My sincere thanks to Brian's wife, Sheila Newbould, for her help in providing background information on him.

\section{References}

Billingham MEJ, Rushton AR (1985) Clozic. In: Rainsford KD (ed) Antirheumatic drugs, experimental agents and clinical aspects of drug use. Boca Raton CRC Press, Fl

Chalmers TM, Kellgren JH, Platt DS (1969) Evaluation in man of fenclozic acid (ICI 54,450, Myelex), a new anti-inflammatory agent. Clin Ann Rheum Dis 28:295

Dudley Hart F, Bain LS, Huskisson EC, Littler TR, Taylor RT (1970) Hepatic effects of fenclozic acid. Ann Rheum Dis 29:684

Franklin TJ, Newbould BB, O'Mant DM, Scott AI, Stacey GJ, Davies GE (1966) A new type of cytotoxic immunosuppressive agent: 3-acetyl-5-(4-fluorobenzylidene)-4-hydroxy-2-oxo-2:5-dihyrothiopen. Nature 210:638-639

Hepworth W, Newbould BB, Platt DS, Stacey GJ (1968) Studies with certain anti-inflammatory and immune-suppressive agents on adjuvant-induced arthritis in rats and other experimental models. Proc Joint Meeting between the Italian and Br Pharmacol Soc

Hepworth W, Newbould BB, Platt DS, Stacey GJ (1968) 2-(4-chlorophenyl) thiazol-4-yl acetic acid ('MYALEX') A new compound with anti-inflammatory, analgesic and anti-pyretic activity. Nat London 221:582-583

Koga T, Sande BV, Yeaton R, Pearson CM (1976) Re-evaluation of inguinal lymph node injection for the production of adjuvant arthritis in the rats. Int Arch Allergy Appl Immunol 51:359-367
Morgan GJ, Peter JB, Newbould BB (1969) Experimental polymyositis. Arth Rheumat 12:317 (Abstract)

Morgan GJ, Peter JB, Newbould BB (1971) Experimental allergic myositis in rats. Arthr Rheum 14:599

Newbould BB (1963) Chemotherapy of arthritis induced in rates by mycobacterial adjuvant. Br J Pharmacol Chem 21:127-136 (621 Citation)

Newbould BB (1963a) Adjuvant-induced arthritis in rats. Proc 1963 Meeting of the British Pharmacological society

Newbould BB (1964) Lymphatic drainage and adjuvant-induced arthritis in rats. Br J Exp Pathol 45:375-383

Newbould BB (1964a) The role of lymph nodes in the development of adjuvant-induced arthritis in rats. Proc British Society for Immunology

Newbould BB (1964c) Role of lymph nodes in adjuvant-induced arthritis in rats. Ann Rheumat Dis

Newbould BB (1964d) Chemotherapeutic suppression of adjuvantinduced arthritis in rats. Br Soc Immunol

Newbould BB (1965a) Production of experimental allergic encephalomyelitis in rats by injections of spinal cord adjuvant into the inguinal lymph nodes. Immunology 9:613-614

Newbould BB (1965b) Chemotherapeutic studies on adjuvantinduced arthritis and allergic encephalomyeltis. Br Pharmacol Soc 12:9-34

Newbould BB (1965c) Suppression of adjuvant-induced arthritis in rats with 2-butoxy carbonyl methylene-4-oxo thiazolidine. Br J Pharmacol Chemother 24:632-640

Newbould BB (1966a) Production of allergic encephalomyelitis and other syndromes involving an immune response by intra-lymph node injection of antigen/adjuvant emulsions. Br Soc Immunol

Newbould BB (1966b) Studies with 3-acetyl-5-(4-fluorobenzylidene)4-hydroxy-2-oxo-2:5-dihyrothiopen (ICI 47,776) on adjuvant induced arthritis allergic encephalomyelitis and allergic thyroiditis in rats. $\mathrm{Br}$ Soc Immunol

Newbould BB (1967) The evaluation and potential utility of compounds which modify the development of adjuvant disease in rats. Invited Am Chem Soc Symp Anti Inflam Comp

Newbould BB (1968a) Attempted inhibition of adjuvant-induced arthritis allergic encephalomyelitis and allergic thyroiditis in rats with certain antisera and chemotherapeutic agents. Proc Meeting of the British Society for Immunology

Newbould BB (1968b) Studies on adjuvant-induced arthritis in rats. Proc International Symposium of Inflammation Biochemistry and Drug Interaction - Como - October 1968

Newbould BB (1969a) Selective suppression with rabbit anti-rat thymocyte serum and rabbit anti-tuberculous serum of adjuvantinduced arthritis (AIA); Expt allergic encephalomyelitis (EAE) and Expt allergic thyroiditis in rats. Arth Rheum 12:31

Newbould BB (1969b) The Phamacology of 2-(4-chlorophenyl) thiazol-4-yl acetic acid (ICI 54,540; 'MYALEX'); a new compound with anti-inflammatory, analgesic and anti-pyretic activity. $\mathrm{Br} \mathrm{J}$ Phamacol 35:487-489

Newbould BB (1980) Risk benefit analysis in drug research: the effect on industry. Proc Society for Drug Res Canterbury

Newbould BB (1981) Implications for management of new directions in pharmaceutical research. Proc Pharma 81:12

Newbould B B (1981) How does marketing research serve the needs of new product research and development. Proc Market Research Meeting Industrial Pharmacists Group London

Newbould BB (1981) Does regulatory control influence the search for new drugs? Proc Br Instit Regu Affairs Symp Guildford

Newbould BB (1986) Life Sciences Phamaceuticals. Proc Anglo-Japn High Technol Industrial Forum

Newbould BB (1986) The future of drug discovery. Proc Society For Drug Research - London 
Newbould B (1986) The Innovation Process - A British Example. Proc Anglo-Japanese High Technology Industrial Forum

Newbould BB (1989) Research results and business success. Proc Management Centre Europe - Zurich -

Newbould BB (1989) ICI Pharmaceuticals. Proc Asian Medical News 10th Anniversary Edition - March 1989

Newbould, B B. (1989) Future Trends in World-wide Pharmaceutical R\&D. Proc Future Trends in Pharmaceutical Research Seminar Bangkok - Thailand - April 1989

Newbould BB (1990) How are medicines discovered? Chapter book Pharmaceutical Medicine

Newbould BB (1992) The birth and growth of the pharmaceutical industry. Proc Duncan Davies Memorial Medal Lecture at the Research and Development Society

Newbould BB (1993) Eastern European R\&D Resources - A Challenge for EIMRA Members. Contribution on Experience to Round Table Meeting - France

Newbould, B B. (1993) The industrialist's perception of post-16 education and training. Proc Ann Assoc Sci

Newbould BB, Kilpatrick R (1959) Some information on long acting sulphonamides. Proc 1959 Meeting of the British Pharmacological Society

Newbould BB, Kilpatrick R (1959) The inhibitory effect of plasma proteins on the antibacterial activity of some new sulphonamides. Proc 1959 of the British Phamacological Society

Newbould BB, Kilpatrick R (1960) Long-acting sulphonamides and protein-binding. Lancet 1960(1):887-891

Newbould BB, Philipps NJ (1992) (1992) An industrial perspective The ICI View. Biologist 39:5

Newbould BB, Pearson CM, Whitehouse MW (2019) Passive transfer of allergic encephalomyelitis in rats-a tool for detecting lateacting immunosuppressants. Inflammopharmacology. https://doi. org/10.1007/s10787-019-00565-w (in press)

Pearson CM (1956) Development of arthritis, periarthritis and periostosis in rats given adjuvants. Proc Soc exp Biol 91:95-101
Pearson CM (1959) Development of arthritis in the rat following injection with adjuvant. In: Shaffer JH, Lo Grippo GA, Chase MW (eds) Mechanisms of hypersensitivity. Little Brown, Boston

Pearson CM, Newbould BB, Whitehouse DJ, Whitehouse M (1969) Conditions required for the cell mediated transfer of adjuvantinduced arthritis, allergic encephalomyelitis and allergic thyroiditis. Arth Rheum 12:322

Pearson CM (1976) Lymphocyte depletion in patients with rheumatoid arthritis. Agents Actions 6:28-31

Pearson CM, Wood FD (1959) Studies of polyarthritis and other lesions induced in rats by injection of mycobacterial adjuvant. General clinical and pathological characteristics and some modifying factors. Arth Rheum 2:440-459

Pearson CM, Wood FD (1963) Studies of arthritis and other lesions in rats by the injection of mycobacterial adjuvant VII. Pathologic details of the arthritis and spondylitis. Am J Path 42:73-95

Rodrigues AVM, Rollison HE, Martin S, Sarda S, Schulz-Utermochl SSS, Gustafsson F, Eakins J, Kenna JG, Wilson ID (2013) In vitro exploration of potential mechanisms of toxicity of the human hepatotoxic drug fenclozic acid. Arch Toxicol 87:1569-1579

Sokoloff MC, Newbould BB (1970) Suppression of experimental allergic encephalomyelitis (EAE) by methotrexate (MTX) with Folinic Acid (FA) rescue. Arthritis Rheum 13:350

Stoerk HC, Bielinski TC, Budzilovich T (1954) Chronic polyarthritis in rats injected with spleen in adjuvants. Am J Path 30:616

Whitehouse DJ, Whitehouse MW, Pearson CM (1969) Passive transfer of adjuvant-induced arthritis and allergic encephalomyelitis in rats using thoracic duct lymphocytes. Nature 224:1322

Whitehouse MW (2007) Adjuvant arthritis 50 years on: the impact of the 1956 article by CM Pearson: Development of arthritis, periarthritis and periostitis in rats given adjuvants. Inflamm Res $56: 133-138$

Publisher's Note Springer Nature remains neutral with regard to jurisdictional claims in published maps and institutional affiliations. 